the closet'. Recently, a High Court rejected a plea to abolish section 377.

On the positive side, the Parliament of India has passed a number of enabling pieces of legislation that have had a direct or indirect effect on the health of its people. These include: the Narcotic Drugs and Psychotropic Substances Act 1985; the Persons with Disabilities Act 1995; the Consumer Protection Act 1986; the Protection of Human Rights Act 1993; the Children Act 1960; and the Juvenile Justice Act 2001 (Khandelwal et al, 2004).

\section{Conclusion}

While in recent years India has enacted many modern, progressive pieces of legislation which have had an indirect effect on the mental health of its people, the main one, the Mental Health Act 1987, has many shortcomings. There have been suggestions from the profession and interested groups on how this can be rectified (Kala, 2004; Sarkar, 2004). The government can invite more suggestions and then submit these to Parliament. However, the problems arising directly out of a shortage of staff will have to wait until the situation improves.

\section{References}

Kala, A. K. (1997) A call for amendment to the licensing provision of the Mental Health Act 1987. Journal of Mental Health and Human Behavior, 2, 101-104.

Kala, A. K. (2004) Why we should opt for a new Mental Health Act and not tinker with the old one. Indian Journal of Psychiatry, 46, 96-98.

Khandelwal, S., Jhingan, H. P., Romesh, S., et al (2004) India: mental health country profile. International Review of Psychiatry, 16, 126-141.

National Human Rights Commission (1999) Quality Assurance in Mental Health. NHRC.

Patel, V. \& Saxena, S. (2003) Psychiatry in India. International Psychiatry, issue 1, July, 16-18.

Sarkar, J. (2004) A new Mental Health Act for India: an ethics based approach. Indian Journal of Psychiatry, 46, 104-114.

World Health Organization (2001) Atlas Country Profiles of Mental Health Resources. WHO. See http://globalatlas.who.int/globalatlas/ predefinedReports/MentalHealth/Files/IN Mental Health Profile.pdf (last accessed 16 April 2007).

\title{
Attention-deficit hyperactivity disorder and use of psychostimulants among children in Turkey
}

\author{
Sahbal Aras ${ }^{1}$ MD and Semih Semin ${ }^{2}$ MD \\ 'Department of Child and Adolescent Psychiatry, Dokuz Eylul University Faculty of Medicine, Inciralti, Izmir, Turkey 35340, \\ emailsahbal.aras@deu.edu.tr \\ ${ }^{2}$ Department of Medical Ethics, Dokuz Eylul University Faculty of Medicine, Inciralti, Izmir, Turkey
}

\begin{abstract}
ecently, the use of psychostimulant medication in children with symptoms of attention-deficit hyperactivity disorder (ADHD) has been subject to extensive debate. The problems faced while assessing and diagnosing ADHD, unnecessary prescribing of psychostimulants, the possible side-effects of psychostimulants on the developing brain, the risk of drug dependency, and the risk of stigmatising children through medicalisation of normal life events are considered among the principal objections to the use of psychostimulant medications. On the other hand, what also need to be taken into account are the increasing evidence on the genetic, biochemical and diagnostic validity of the disorder, the data showing the therapeutic effects of psychostimulants and the rarity of the above-mentioned side-effects, as well as the ethical problems created by insufficient treatment of children because of the concerns of parents. A critical evaluation of these conflicting opinions by mental health professionals might contribute to the application of ethical principles. While making this kind of evaluation, it is important to pay
\end{abstract}

regard to the specific sociocultural features of the country, as well as the prevailing worldwide discussion.

\section{Sociocultural overview of Turkey}

Turkey, a secular state which wants to be a member of the European Union, is at the crossroads of two continents. Twothirds of its population of 70 million live in urban areas and about a quarter live below the poverty limit. According the 2005 'world indicators' of the World Bank, Turkey is 55th among 124 countries with respect to unfair distribution of income (Radikal, 2005).

One-third of the population in Turkey is 15 years of age or younger and the number of students in primary education is 10.5 million. The average class size is about $35-40$, whereas the appropriate number of students in a class is generally considered to be 15-20. Since 1998, the duration of compulsory education has increased from 5 years to 8 years. Nevertheless, $10 \%$ of children $(13 \%$ for 
girls and $7 \%$ for boys) of primary education age cannot attend school.

There are problems in directing students towards vocational education. In most higher-income countries, two-thirds of students are in vocational education, but in Turkey the proportion is only one-third. As a result, in the year 2005, 1730850 students took the Student Selection Examination for university, but only $23.5 \%$ of these found the opportunity to attend any college or university (CNN TURK, 2005). Also, higher education does not simply equate with job opportunity, as approximately one-third of high-school graduates are unemployed. This competitive economic and educational environment means that a great deal of importance is attached to academic performance. Families think that academic success is essential to social status, which in turn increases the anxiety of families and teachers about children who might have educational difficulties. Meanwhile, ordinary schools have no facility for children who have intellectual disability or other special needs. There are examples of labelling and exclusion of those children who have special needs.

The prevalence of illiteracy among women in Turkey is one in five of the adult population, while it is one in eight of the total adult population (State Institute of Statistics, 2004). Turkey is one of the foremost countries in television viewing: the average time spent watching is about 4 hours per day per person. About one-fifth of all television news broadcasts include homicide, suicide or violence.

Migration from rural to urban areas and from eastern to western cities, breaking the traditional family structure, and violence in family or in school, high rates of unemployment and poverty as well as unsatisfactory conditions of education may be counted among factors which increase the risk of psychiatric problems among children and young people in Turkey. Visits from doctors to attend children with reported inattention and hyperactivity increase with these sociocultural circumstances. There is considerable discussion in the media about ADHD and the scientific studies of it.

\section{Prevalence studies of ADHD in Turkey}

There are relatively few studies of the clinical features of ADHD in Turkey. In a community-based study carried out in the city centre of Sivas, $8.1 \%$ of 1425 students aged 5-15 years were found to fulfil the DSM-IV criteria for ADHD, according to the ratings of their teachers and parents (Ersan et al, 2004). In the child and adolescent psychiatry clinic of Ankara University, 8.6\% of the 1556 cases seen in the out-patient unit in 22 months were diagnosed with ADHD, making it the third most common diagnosis, after anxiety and affective disorders (Senol \& Sener, 1998). In a university child psychiatry out-patient unit in Trabzon, $37.3 \%$ of 43 adolescents with attention deficit symptoms at admission were diagnosed with ADHD (Oner et al, 2002).

In a study by the first author (Aras et al, 2004) carried out with 822 new patients presenting to the child psychiatry out-patient clinic at Dokuz Eylul University Hospital, it was found that presentations with 'distractibility and overactivity' accounted for $27.7 \%$ of the total, the rate of ADHD was $12.5 \%$ and the rate of psychostimulant use was $3 \%$. The rate of psychostimulant use and ADHD diagnosis had shown a 7- to 10-fold increase in the same department over the course of 10 years. Symptoms of ADHD were the most common presenting complaints and ADHD was the most common disorder. Boys were predominantly affected: $87.4 \%$ of children with ADHD and $84.0 \%$ of children using psychostimulants were males. In children with $A D H D$, the rate of medication use was $38.8 \%$ and the rate of psychostimulant treatment was $24.3 \%$.

\section{The role of psychostimulant medication}

Recently, the Ministry of Education considered screening all the country's school students for ADHD. Such communitybased programmes are regarded as effective methods for the advertisement of drug products and as a consequence drug use may become widespread. This plan in Turkey was widely discussed and criticised because of the risk of labelling children with ADHD and increasing psychostimulant use.

Up to 2005, methylphenidate was the only psychostimulant available within Turkey. Psychostimulants in Turkey can be obtained only with special receipts used for 'narcotic substances and medication under state control' since 1985 and their distribution is controlled by the state. The amount of methylphenidate imported was $2 \mathrm{~kg}$ in 1998, but this had increased to $23 \mathrm{~kg}$ by 2002 (International Narcotics Control Board, 2004).

It was reported that approximately 10000 children were using methylphenidate in 2002 (Aktas, 2003). When $20 \mathrm{mg} /$ day doses are used, the monthly cost of methylphenidate (Ritalin) is approximately US $\$ 12$. If pharmacotherapy becomes more widespread, psychostimulants could become a profitable group of drugs in Turkey, with its predominantly young population. This fact could accelerate the importation of a wider range of psychostimulants; at the beginning of 2005, a longer-acting and more expensive form of methylphenidate came on the market.

In Turkey, psychostimulants can be prescribed only by specialists in child and adolescent psychiatry, psychiatry, neurology and child neurology. The total number of child psychiatrists and residents is about 200, and most of them are in the bigger cities and university clinics. Especially in state hospitals, a child psychiatrist has to see $30-40$ patients a day, limiting the length of a visit to 10-15 minutes. Meanwhile, other doctors who are able to prescribe psychostimulant medication have limited education regarding ADHD. Taking the patient history and the administration of teacher or parent rating scales are the main procedures used to diagnose ADHD. In Turkey, many children have received a 'diagnosis' of 'possible ADHD' from their parents and teachers before they are even seen by a doctor. Visiting a doctor with this label may result in a rapid diagnosis and treatment plan, without detailed evaluation of psychosocial and developmental factors.

As psychostimulants can improve cognitive and motor functioning in normal people, there are worries about their use in the general population to increase performance (Searight \& McLaren, 1998). In Turkey's socio-economic circumstances, for some children with symptoms of ADHD, medication can be prescribed inappropriately, to increase 
school performance according to the expectations of parents and teachers. Such prescriptions for children with academic or behavioural difficulties may serve to hide the responsibilities of parents, schools and the public for the child's problems. Besides inadequate educational conditions, having a small number of child psychiatrists can make it harder to plan rational medication use in ADHD. On the other hand, many children whose symptoms are severe enough for a diagnosis of ADHD have difficulties in obtaining psychiatric care.

\section{Conclusion}

There are limited data regarding the prevalence, comorbidity, effects of treatment modalities, useful diagnostic procedures or diagnostic criteria for ADHD in Turkey. In order to receive the correct diagnosis and to find appropriate treatment, these data are very important in a country like Turkey, whose population is culturally different from those of most higher-income countries (Rohde, 2002). The evaluation and the treatment phase should take account of cultural and socio-economic variables. Unlike in some higher-income countries with better measures of education and health, it is not realistic to expect the psychosocial and behavioural problems of Turkish children to be resolved by prescribing pills. Education and health policies that take into account current debates in the world on ADHD also need to be implemented in Turkey.

\section{References}

Aktas, U. (2003) Difficult issue: hyperactivity. Radikal (newspaper), 23 December.

Aras, S., Tas, F. V. \& Unlu, G. (2004) Psychotropic medication practices of a child and adolescent psychiatry out-patient clinic in Turkey. (Data on file.)

CNN TURK (2005) Student Selection Examination marathon has finished, 18 June. Available at http://www.cnnturk.com/arama/haber_detay.asp?PID= 00318\&haberlD=104915 (in Turkish) (last accessed 16 April 2007).

Ersan, E. E., Dogan. O., Dogan, S., et al (2004) The distribution of symptoms of attention-deficit/hyperactivity disorder and oppositional defiant disorder in school age children in Turkey. European Child and Adolescent Psychiatry, 13, 354-361.

International Narcotics Control Board (2004) Psychotropic substances 2004 (substances listed in Schedule II). Available at http://www.incb.org/pdf/e/ tr/psy/2004/psychotropics_schedule_b.pdf (last accessed 16 April 2007).

Oner, O., Oncu, B., Sagduyu, G., et al (2002) Dikkatsizlik yakınmasıyla basvuran ergenlerin aldıkları tanılar. [Psychiatric diagnoses among adolescents with attention problems.] Turkish Journal of Child and Adolescent Mental Health, 9, 167-171.

Radikal (2005) Distribution of income is worse than in Tanzania, 20 April. Available at http://www.radikal.com.tr/haber.php?haberno=150216 (in Turkish) (last accessed 16 April 2007).

Rohde, L. A. (2002) ADHD in Brazil: the DSM-IV criteria in a culturally different population. Journal of the American Academy of Child and Adolescent Psychiatry, 41, 1131-1133.

Searight, H. R. \& McLaren, A. L. (1998) Attention-deficit hyperactivity disorder: the medicalization of misbehavior. Journal of Clinical Psychology in Medical Settings, 5, 467-495.

Senol, S. \& Sener, S. (1998) Attention deficit hyperactivity disorder. In Psikiyatri Temel Kitabi [Basic Book of Psychiatry], Volume II (eds C. Güleç \& E. Köroglu), pp. 119-130. Hekimler Yayin Birligi.

State Institute of Statistics (2004) Available at http://nkg.die.gov.tr (last accessed 16 April 2007)

\section{Intellectual disability: an Italian perspective}

\section{Giampaolo La Malfa and Pierluigi Cabras}

Psychiatrists, Neurologists, Department of Neurological and Psychiatric Science AOU Careggi, University of Florence, Italy, emailgplamalfa@videosoft.it

\begin{abstract}
taly is a country that has a very long tradition, dating back to the Middle Ages, of offering assistance to people with all kinds of disabilities. The approach taken to intellectual disability in recent times can be divided into two periods: before and after the enactment of Law 180 in 1978. That law set in train a profound reform of Italy's public sector psychiatric care, which principally involved the closure of the psychiatric hospitals and the establishment of a system of community care.

Before this law, people with intellectual disabilities were generally admitted to psychiatric hospitals, not only because of their pathology but also because they were considered 'deviant'. After the closure of the psychiatric hospitals, Italian psychiatry seemed to lose any interest in the care adults with intellectual disabilities and that still seems to be true of the discipline today.
\end{abstract}

\section{Definitions of disability}

Under Law 104 of 1992, 'disability' is defined as a loss of the ability of the person to perform basic daily activities unaided. However, this is just a legal definition and differs in its parameters from the eligibility criteria that are used to determine whether an individual is able to receive state assistance in the form of services and benefits. For the latter purpose, 'invalidity' gives the right to receive financial benefits when an intellectual disability is a consequence of biological damage. That is, there is no reference to general self-sufficiency. In fact, an individual's 'disability' is rarely used as a criterion for the receipt of social care or benefit; indeed, the individual's social insurance status is much more often the determining factor, as opposed to any functional limitation (such as intellectual disability, psychiatric disorder or dementia). 